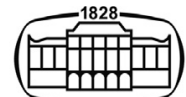

AKADÉMIAI KIADÓ

Acta Chromatographica

33 (2021) 2, 188-194

DOI:

$10.1556 / 1326.2020 .00778$

(c) 2020 The Authors

\title{
Development and validation of method for determination of organophosphorus pesticides traces in liver sample by GC-MS/MS-ion trap
}

\author{
ISKRA BONEVA ${ }^{1}$, SPASKA YANEVA ${ }^{2}$ and \\ DANCHO DANALEV ${ }^{2 *}$ (1) \\ ${ }^{1}$ Central Laboratory of Veterinary Control and Ecology (CLVCE), Bulgarian Food Safety Agency, 5 \\ Iskarsko Shousse Str, Sofia, Bulgaria \\ ${ }^{2}$ University of Chemical Technology and Metallurgy, 8 blvd. Kliment Ohridski, Sofia, 1756, Bulgaria
}

Received: March 27, 2020 • Accepted: May 03, 2020

Published online: July 17, 2020

\section{ORIGINAL RESEARCH} PAPER

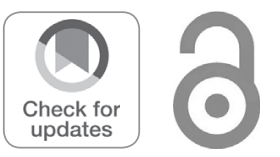

\section{ABSTRACT}

A method for simultaneous determination of trace of four organophosphorus pesticides residues in animal liver samples has been developed and validated. This method is based on the preliminary sample preparation using extraction of target compound with a mixture of toluene-cyclohexane by means of up-to-date accelerated solvent extraction (ASE), liquid-liquid partitioning with acetonitrile and hexane, additional clean up step using QuEChERS method. Further the obtained analytes are determined by gas chromatography with ion-trap detector. The validation of the method is performed in accordance with the recommendations in Document SANTE/11945/2015 and it meets the acceptability criteria for precision, mean recovery and limits of quantification. The samples were investigated by analysing blank liver samples and samples spiked with the target analytes chlorpyrifos-methyl, parathion and pirimiphos-methyl at levels of 25, 50, and $75 \mathrm{ng} / \mathrm{g}$ and with diazinon at levels of 15, 30, and $45 \mathrm{ng} / \mathrm{g}$. The recovery for all compounds were in the range from 73 to $104 \%$ which perfectly fit with requirements of documents and European legislations. The repeatability and within-laboratory reproducibility also reveal acceptable in documents coefficient of variation and uncertainty less than 20 and $18 \%$, respectively. The limits of quantification were less than $3 \mathrm{ng} / \mathrm{g}$ for all compounds and allowed determination of residues below the maximum residue levels (MRLs) set in Regulation (EC) No 396/2005.
\end{abstract}

\section{KEYWORDS}

organophosphorus pesticides, GC-MS/MS ion-trap, food analysis, liver samples

\section{INTRODUCTION}

Pesticides are organic molecules largely used in agriculture for plant support during the process of cultivation [1]. They include wide class of compounds but the most prominent for plant treatment are chlorine and phosphor containing molecules as well as N-methylcarbamade. Organophosphorus pesticides (OPPs) are of a large interest because together with $\mathrm{N}$-methylcarbamates they slowly replace organochlorines due to the established bioaccumulation of the latter. Typically OPPs are amides, esters or thiol derivatives of phosphoric or phosphonic acid. They are easily hydrolysed and thus do not persist in the environment for a very long time. However, their various toxicity (they act as inhibitors of acetylcholinesterase enzyme) as well as possibility for accumulation in the food chain can cause a risk for human health [2-4].

The presence of these compounds in the food have led to established maximum residue levels (MRLs) in or on food and feed of plant and animal origin are set at Regulation (EC) $\mathrm{N}^{\mathrm{o}}$ 396/2005. All Member States must take and analyse samples for needs of National Monitoring Plan according to Council Directive 96/23/EC of 29 April 1996 on measures to

*Corresponding author. Tel.: +35928163310 .

E-mail: ddanalev@uctm.edu 
monitor certain substances and residues thereof in live animals and animal products. On the other hand concerning a coordinated multiannual control program of the Union the pesticide in food are established in the Commission implementing regulation (EU) 2018/555 [5]. In order to be able to carry out the monitoring programs, it is necessary for laboratories to create a really applicable method in laboratory practice for analysis of OPPs which meets the requirements of European legislation. In this respect the laboratories developed and validate own methods.

Nowadays, rapid methods for determination of pesticides are very preferable. Biosensors are widely used as they are quick and easy to use. At the same time they offer quick response and can be validated with appropriate parameters according to the legislation, comparable with chromatographic techniques $[6,7]$. The main disadvantage of biosensors is that they report results for entire group of pesticides presented in the sample, but not for individual target analyte.

The process of analytical method developing include two main steps: sample preparation (including matrix pretreatment) and analytical determination of target compounds. Traditionally, the preliminary treatment of complex samples, such as liver, is carried out in a sequence of extraction and clean-up steps. Ledoux summarized that the most widely used pesticide extraction technique from foods of animal origin are: solid-liquid extraction, traditional Soxhlet extraction method, accelerated solvent extraction (ASE), microwave-assisted extraction, matrix solid-phase dispersion and the clean-up steps are mainly performed by: freezing centrifugation, liquidliquid partitioning, gel permeation chromatography (GPC) and solid-phase extraction [8].

Nowadays, QuEChERS (quick, easy, cheap, effective, rugged and safe) methods are developed and widely used for extraction and clean up procedure of food samples. The ruggedness characteristics of the QuEChERS approach have been thoroughly evaluated in the original [9] and several more publications [10-13]. All these steps during the sample preparation, aid the instrumental analyses - the cleaner the extract, the lower the determined concentration by the detector [14].

Therefore, a modified QuEChERS method, which can be applied for liver, would be appropriate alternative for laboratory's routine work, to save time and money which is extremely important for the final prize of proposed analysis. Also QuEChERS AOAC 2007.01 was selected as the most suitable protocol for routine determination of residues of 16 pesticides most commonly used for fruits treatment during the citrus production through liquid chromatography coupled to tandem mass-spectrometry (LC-MS/MS) [15]. After the extraction and purification procedures, pesticides need to be separated and further determined. The GC coupled with mass spectrometric detectors, including single quadrupole, ion trap, and triple quadrupole mass-spectrometers, has been adapted for analysis of pesticide residues in foods of animal origin $[8,16]$.

The aim of this study is focused on the development of easy and quick method for extraction and cleans up of OPPs residues in liver and determination by GC-MS/MS which to reflect to an appropriate final prize of proposed analysis - a very important part for consumers of this service. The fat content in liver is the most important step of sample preparation appears to be clean up. Liquid-liquid partition is appropriate method for fat removal [16], but additional clean step is needed because of remaining fat precipitation in the defatted extract. The liquid-liquid partition and QuEChERS methodology, proposed in this paper, is independent of special equipment and also makes the handling with the samples very easy. QuEChERS methodology (used clean-up steps) is quick, easy, cheap, effective, but it has been applied with success on several non-fatty and low-fatty food matrices. Recently modified QuEChERS methodology has been applied in high fatty food as meat and fish as additional cleanup step with combination with liquid-liquid partitioning $[17,18]$.

\section{MATERIAL AND METHODS}

\section{Solvents and reagents}

Hexane, cyclohexane, acetonitrile, toluene (gradient grade) and anhydrous sodium sulfate were supplied by Supelco (USA). The sodium sulfate was heated overnight at $600{ }^{\circ} \mathrm{C}$ and then $1 \%$ distilled water was added. Silica gel (obtain from Merck, Germany), 70-30 mesh, was also heated overnight at $600{ }^{\circ} \mathrm{C}$, and deactivated with $5 \%$ distilled water. Magnesium sulfate (reagent grade, obtain from Merck, Germany), DSC-18 (obtain from Merck, Germany), primary and secondary amine (PSA) bulk, from Supelco (USA) Helium (99,999\% purity), is used as carrier gas.

\section{Analytical standards}

Chlorpyrifos-methyl (98\% purity); Parathion (99\% purity); Pirimiphos-methyl (99\% purity); and Diazinon (99\%. purity) All of them were purchased from Dr Ehrenstorfer (Germany), Mirex- (purity $>96 \%$ ) is obtained from Sigma Aldrich, Germany. Primary stock solutions of each analyte were prepared in hexane at a concentration of $1,000 \mu \mathrm{g} / \mathrm{mL}$, intermediate single standard solutions were prepared in hexane at a concentration of $1 \mu \mathrm{g} / \mathrm{mL}$ and the multi-standard solution is also prepared in hexane with concentrations of all pesticides was prepared by appropriate dilutions.

These mixed working standard solutions with appropriate OPPs levels were used for making calibration curve, studying linearity and spiking blank liver samples. Mirex internal standard solution of $1 \mu \mathrm{g} / \mathrm{mL}$.

\section{Equipment}

Gas chromatograph (Varian 431-GC, USA), Ion Trap Mass Spectrometer (Varian 220 MS, USA), capillary column DB-5 MS (Agilent J\&W, USA) (length of $30 \mathrm{~m}, 0.25 \mathrm{~mm}$ internal diameter, film thickness $0.25 \mu \mathrm{m}$ ), extraction of samples ASE technique using Dionex ASE 300 extractor., Analytical 
Table 1. Identification data of target OPPs by GC-MS/MS

\begin{tabular}{|c|c|c|c|c|c|}
\hline Compounds & $\mathrm{Mw}[\mathrm{g} / \mathrm{mol}]$ & $\begin{array}{l}\text { Retention } \\
\text { time [min] }\end{array}$ & $\begin{array}{l}\text { Precursor } \\
\text { ion }[\mathrm{m} / \mathrm{z}]\end{array}$ & Product ion $[\mathrm{m} / z]$ & $\begin{array}{c}\text { Excitation } \\
\text { amplitude [V] }\end{array}$ \\
\hline $\begin{array}{l}\text { chlorpyriphos- } \\
\text { methyl }\end{array}$ & 350.59 & 18,501 & 286 & $101 ; 139 ; 223$ & 89 \\
\hline parathion & 291.26 & 21,056 & 292 & $136 ; 144 ; 233$ & 95 \\
\hline pirimiphos-methyl & 305.33 & 19,786 & 306 & $152 ; 180$ & 100 \\
\hline diazinon & 304.34 & 16,678 & 305 & $121 ; 145$ & 98 \\
\hline
\end{tabular}

balances (Sartorius, PB $221 \mathrm{~S}$ and Sartorius, PB 610), Digital ULTRA-TURRAX (IKA 3565001 T 25).

\section{ANALYTICAL METHOD}

\section{Sample preparation}

Extraction. Liver is homogenizing by means of ultra-turrax IKA T25 before extraction. Weigh $10 \mathrm{~g}$ of the homogenized liver sample, add about $5 \mathrm{~g}$ of anhydrous sodium sulfate, comminute thoroughly in a mortar and then transfer into cell of ASE for the extraction. The total extraction is performed using $135 \mathrm{~mL}$ solvent per sample (toluene/cyclohexane $50 / 50(\mathrm{v} / \mathrm{v})$ at $100{ }^{\circ} \mathrm{C}$ and pressure $1,500 \mathrm{psi}$. The collected extract are transferred into a flask and rotaryevaporated the solvents.

Liquid-liquid partitioning with acetonitrile and hexane. The concentrated extract is carefully transferred with $5 \mathrm{ml}$ of hexane to a $50 \mathrm{~mL}$ volumetric flask and mixed well. Add 50 $\mu \mathrm{L}$ internal standard (Mirex) from $1 \mu \mathrm{g} / \mathrm{mL}$ stock solution and wait $5 \mathrm{~min}$. Afterwards, a double extraction with acetonitrile is done as follows: add $5 \mathrm{~mL}$ of acetonitrile and vortex for about $2 \mathrm{~min}$, centrifuge for $2 \mathrm{~min}$ at 2,000 rpm for better separation of the layers (hexane and acetonitrile). Acetonitrile extracts were combined into $15 \mathrm{~mL}$ centrifuge tube and evaporated to dryness under nitrogen at $50{ }^{\circ} \mathrm{C}$ water bath.

Additional purification step with QuEChERS method. The extract after evaporation was dissolved with $2 \mathrm{~mL}$ acetonitrile and $100 \mathrm{mg}$ PSA, $400 \mathrm{mg} \mathrm{MgSO}_{4}$, and $100 \mathrm{mg}$ DSC-18 bulk pack (silica gel base material, Polymerically bonded, octadecyl (18\%C), endcapped) were added into tube for clean up. The sample was again vortex for $1 \mathrm{~min}$ and centrifuges for $3 \mathrm{~min}$ at $3,000 \mathrm{rpm}$. The final eluent was collected and evaporated to dryness under nitrogen and reconstituted with $100 \mu \mathrm{L}$ of cyclohexane to determine by GC.

\section{Chromatographic conditions}

Split/splitless injector was heated at $250{ }^{\circ} \mathrm{C}$ and equipped with a CP 8400 autosampler (Varian, USA); injection volume was $2 \mu \mathrm{L}$. The following oven temperature programme was used: $95^{\circ} \mathrm{C}(1 \mathrm{~min}), 15^{\circ} \mathrm{C} / \mathrm{min}$ to $120{ }^{\circ} \mathrm{C}(2 \mathrm{~min}), 5{ }^{\circ} \mathrm{C} /$ min to $285^{\circ} \mathrm{C}(5 \mathrm{~min}), 5{ }^{\circ} \mathrm{C} / \mathrm{min}$. The carrier gas (helium) with flow rate of $1 \mathrm{~mL} / \mathrm{min}$. Transfer line and ion trap temperatures was 280 and $150{ }^{\circ} \mathrm{C}$ respectively.

\section{Method validation}

The liver samples free from pesticide residues were used as blank material for validation procedures. The validation is performed according to the recommendations in procedure of SANTE/12682/2019 [19]. The calibration curve was prepared, using blank material spiked at six levels corresponding to concentrations between 0 and 2 MRLs for all analytes. Blank liver samples spiked with OPPs at the levels corresponding to $0.5,1.0$ and 1.5 MRLs $(25,50,75 \mathrm{ng} / \mathrm{g}$ for chlorpyrifos-methyl; parathion, pirimiphos-methyl and 15, $30,45 \mathrm{ng} / \mathrm{g}$ for diazinon) were used for evaluation of recovery, repeatability, within-laboratory reproducibility and uncertainty. Spiked samples at each concentration level were analysed in three series, each on the different day, and each in six replicates. The obtained validation parameters are presented in Table 1.

Regression curve for all pesticides showed good linearity with determination coefficients $\left(R^{2}\right)$ values of at least 0.98 . The proportion of analyte remaining at the point of the final determination, following its addition (usually to a blank sample) immediately prior to extraction. Usually expressed as a percentage [19]. Average recovery was calculated by comparing the determined concentrations of spiked samples to the target level. The reported uncertainty was an expanded uncertainty with a coverage factor of 2 to give a level of confidence of approximately 95\%, in accordance with the recommendations of [20]. The limit of quantification (LOQ) is determined as the lowest concentration level that can be validated with acceptable values for recovery and precision. The requirement for LOQ at [19] is LOQ $\leq$ MRL. Results are summarized in Table 2.

\section{RESULTS AND DISCUSSION}

At the beginning of our study several samples were spiked with target compounds. The spiked samples were subjected to preliminary treatment described in the Material and Methods section and the obtained chromatograms and confirmatory spectra are presented on Fig. 1.

It can be seen that the developed chromatographic conditions as well as sample preparation procedure do not show any interference peaks of other matrix components in the retention times of target analytes. In order to confirm 
Table 2. Limit of quantitation for organophosphorus pesticides in liver by GC-MS/MS

\begin{tabular}{|c|c|c|c|c|}
\hline Compounds & MRL [ng/g] & $\mathrm{LOQ}^{\mathrm{a}}[\mathrm{ng} / \mathrm{g}]$ & Recovery [\%] $(n=20)$ & $\begin{array}{r}\text { Within-laboratory reproducibility } \\
\left(\mathrm{RSD}_{\mathrm{wR}}\right) \operatorname{RSD}[\%],(n=20)\end{array}$ \\
\hline chlorpiryphos-methyl & 50 & 1.0 & 98.3 & 8.7 \\
\hline parathion & 50 & 2.7 & 101.7 & 10.3 \\
\hline pirimiphos-methyl & 50 & 0.7 & 81.2 & 7.8 \\
\hline diazinon & 30 & 0.9 & 82.4 & 9.1 \\
\hline
\end{tabular}

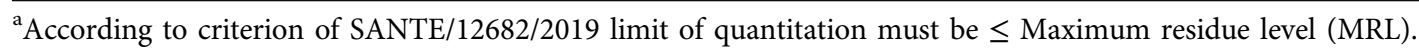

that the developed method is suitable for its intended use, and to fulfil the aim of this study, the validation process was further carried out.

The requirements when MS/MS detector is used for determination of pesticides are at least two product ions to be detected for structure confirmation. Data relating to the identification of target OPPs, are presented in Table 1.

The optimized conditions for molecular ions fragmentation for each compound allowed to obtain minimum two fragments for target compounds, which meets the requirement of document SANTE 11945/2015. Three fragments were obtained for chlorpyrifos-methyl and parathion. It is important to mention that the molecular ions of pirimiphosmethyl and diazinon are larger than $300(\mathrm{~m} / z 306$ and 305, respectively), which makes it difficult to be break down of fragments of the ion-trap detector. From the obtained spectra of these two compounds, it can be seen that despite the maximum collision energy molecular ions only decreased in intensity, but still present in the spectrum at $100 \%$.
The quantification of OPPs was obtained using matrix based calibration curve with organochlorine pesticide mirex as an internal standard. Mirex is chosen as it is not expected to be present at the sample, has similar retention time and is easy to extract by means of the used sample preparation. The recoveries of the individual compounds varied from 81 to $102 \%$ which were satisfactory according to document requirements.

Repeatability of measurements and within-laboratory reproducibility, expressed as relative standard deviation (RSDwR) were lower than $20 \%$ for all compounds.

Table 2 summarizes data for MRLs, LOQ, recovery and repeatability calculated at LOQ-level. The LOQ is established between 0.7 and $2.7 \mathrm{ng} / \mathrm{g}$ for all compounds, considerably lower than the MRLs.

The LOQ was defined as the smallest concentration of analyte that can be quantified with acceptable validation parameters (trueness) and precision. In order to determine the LOQ level, 20 liver samples were spiked with standard
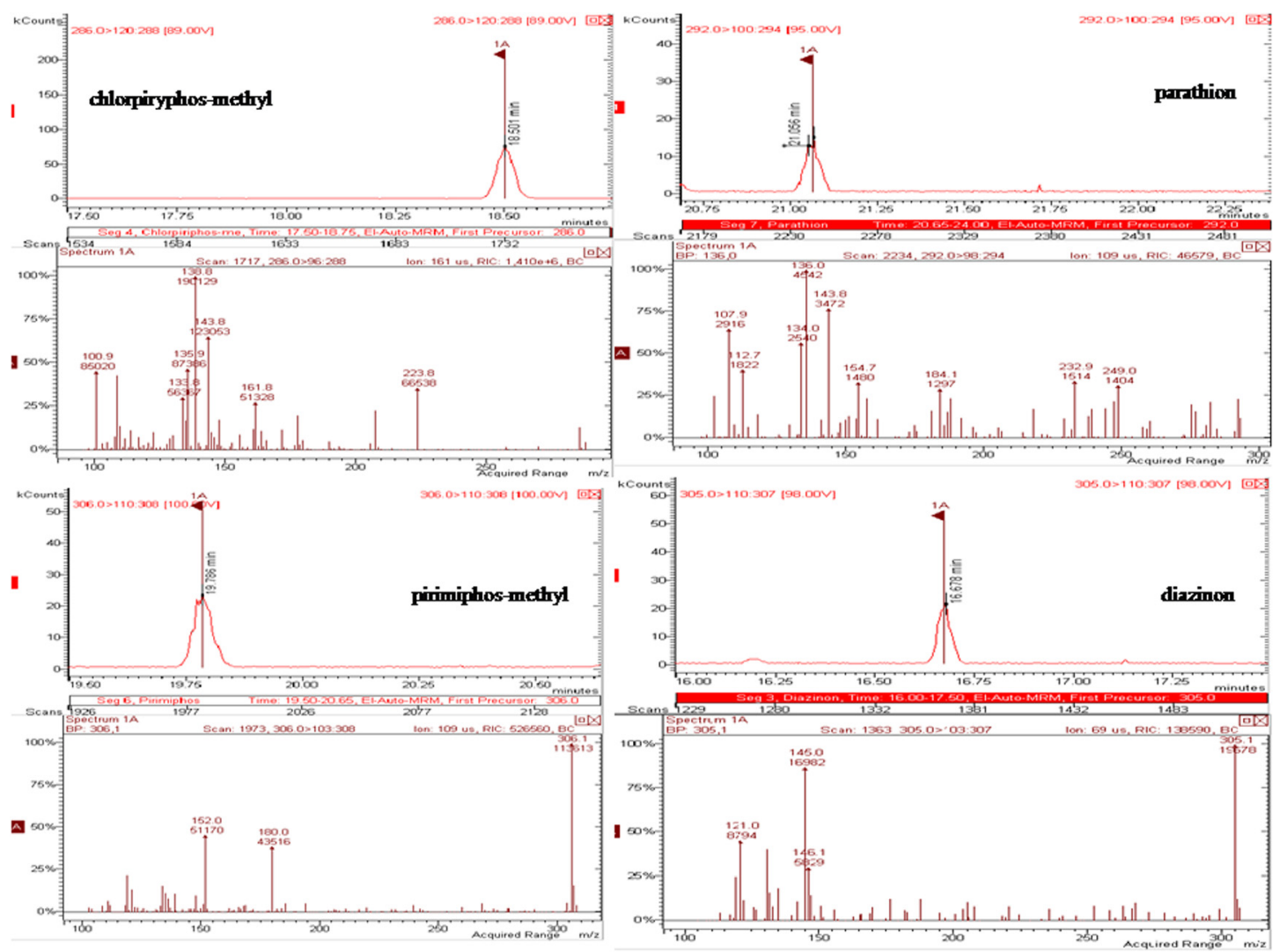

Fig. 1. Chromatograms and MS spectra of target organophosphorus pesticides in liver sample on a LOQ level 
Table 3. The characteristics of linearity for studied substances in investigated range

\begin{tabular}{lccc}
\hline Name & $\begin{array}{c}\text { Regression } \\
\text { equation }\end{array}$ & ${ }^{\mathrm{a}} R^{2}$ & $\begin{array}{c}\text { working range } \\
{[\mathrm{ng} / \mathrm{g}]}\end{array}$ \\
\hline chlorpiryphos-methyl & $61.4 \times+0.08$ & 0.99 & $1.0-75.0$ \\
parathion & $17.5 \times+0.02$ & 0.97 & $2.7-75.0$ \\
pirimiphos-methyl & $85.6 \times+0.13$ & 0.99 & $0.7-75.0$ \\
diazinon & $55.5 \times-0.04$ & 0.97 & $0.9-45.0$ \\
\hline
\end{tabular}

aAccording to Document SANTE/12682/2019 the criteria is $R^{2} \geq 0.95$.

solution and then analysed. The results are summarized in Table 2. All LOQ values are below the MRLs, which fully covers the requirement. The lowest LOQ is for pirimiphosmethyl $-0.9 \mathrm{ng} / \mathrm{g}$, which is more than 30 times less than the MRL.

The linear range is determined as function between the concentration of the pesticides and the ratio of its area to the internal standard (IS). The calibration method is a procedural calibration curve with spiked samples using the internal standard method for calculation. Five increasing concentrations of the pesticides were determine as a function of the MRL and a blank sample was used for zero level 0.0; LOQ; 0.5 multiplied by MRL; 1,0 multiplied by MRL; 1,5 multiplied by MRL; 2.0 multiplied by MRL. The concentration of IS in each sample is equal. The data for linearity is summarized in Table 3.

The data presented in Table 3 shown very good linearity for all target pesticides. The range from LOQ up to 2.0 times MRL is covered with determination coefficient $R^{2} \geq 0.95$.

Further the investigation for recovery, accuracy and uncertainty were realized. The obtained data are in Table 4.

Recovery rate is related to the selection of suitable sample preparation. The lowest recovery was obtained for parathion at a validation level $1-73 \%$, and the highest recovery was for diazinon in the highest concentration of validation - 104\%, but all obtained results cover the criteria of European legislation. Recoveries exceeding 100\% are mainly obtained due to the matrix effect. Kiljanek and co-authors developed a method for analysis of OPPs in liver by GC-NPD, using GPC followed by silica gel column to purify the samples [21]. Despite the application of the GPC system, which is expensive and solvent and time consuming, their reported results for recoveries are in the ranged from $76 \%$ to $105 \%$ [21]. These results are comparable to those obtained in the present work, using a much faster and easier sample preparation method. All repeatability and reproducibility results are below $20 \%$ and even below $10 \%$, fully meeting the criterion. Reproducibility is related to the applicability of the method under different conditions, such as different operator, different time or place of analysis. The data shows that the method is stable and changing the external conditions does not affect the results. The measurement uncertainty value in document SANTE/12682/2019 is calculated as the average of the uncertainties reported by all laboratories in the European Union, participating in inter-laboratory tests for the analysis of pesticides in food, organized by the European Reference Laboratory.

The presented method allowed a simultaneous determination of four organophosphorus pesticides in animal liver by GC-MS/MS ion trap. European Regulations required the monitoring programs for control of pesticide residues based on effective methods with high level of quality control at the same time. Therefore, we have sought a new sample preparation procedure with low time and solvent consumption. We have used extraction with ASE - technique and have implemented liquid-liquid partitioning to remove fat content in extracts followed by QuEChERS purification step. There are several solvents used for liquid-liquid partitioning described in the literature. Our experiments included two possible extraction systems acetonitrile:hexane 1:1 (v/v) or acetonitrile:acetone 1:1 (v/v) by liquid-liquid partitioning. The acetonitrile:hexane combination was preferred because of better separation between the two solvents and easily removal of hexane layer. Acetonitrile is polar enough to

Table 4. Recovery, repeatability, reproducibility and uncertainty obtained for target OPPs in liver by GC-MS/MS

\begin{tabular}{|c|c|c|c|c|c|}
\hline Pesticide & $\begin{array}{l}\text { Spike level } \\
{[\mathrm{ng} / \mathrm{g}]}\end{array}$ & $\begin{array}{l}\text { Recovery [\%] } \\
\quad(n=18)\end{array}$ & $\begin{array}{c}\text { Repeatability } \\
\text { RSDr [\%], }(n=6)\end{array}$ & $\begin{array}{l}\text { Within laboratory } \\
\text { reproducibility } \\
\mathrm{RSD}_{\mathrm{wR}}[\%](n=18)\end{array}$ & $\begin{array}{c}\text { Uncertainty } \\
{[\%]}\end{array}$ \\
\hline \multirow[t]{3}{*}{ chlorpiriphos-methyl } & 25 & 97.8 & 4.31 & 6.12 & 6.07 \\
\hline & 50 & 99.0 & 7.32 & 7.64 & 6.27 \\
\hline & 75 & 101.2 & 6.63 & 6.51 & 4.46 \\
\hline \multirow[t]{3}{*}{ parathion } & 25 & 72.6 & 6.61 & 8.81 & 7.41 \\
\hline & 50 & 99.8 & 8.55 & 8.87 & 7.23 \\
\hline & 75 & 97.4 & 7.80 & 9.54 & 5.55 \\
\hline \multirow[t]{3}{*}{ pirimiphos-methyl } & 25 & 99.9 & 3.02 & 5.90 & 6.10 \\
\hline & 50 & 98.4 & 4.41 & 6.27 & 5.55 \\
\hline & 75 & 99.3 & 2.56 & 2.54 & 2.50 \\
\hline \multirow[t]{3}{*}{ diazinon } & 15 & 78.2 & 5.33 & 7.46 & 6.95 \\
\hline & 30 & 101.8 & 7.99 & 8.05 & 6.69 \\
\hline & 45 & 103.5 & 5.43 & 5.80 & 3.75 \\
\hline
\end{tabular}

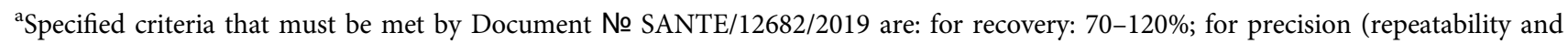
reproducibility): $\leq 20 \%$ and for uncertainty: $\leq 50 \%$. 
minimize the amount of co-extractive fat and is non-polar enough to extract with efficiency lipophilic pesticides from matrix [22-24]. The main amounts of lipids transfers into the hexane layer are successfully eliminated. We tested two options for additional clean up steps: using silica gel column and QuEChERS technique. Both clean up techniques proposed good purification but the results of Silica-gel clean up obtained less than $35 \%$ recovery.

\section{CONCLUSIONS}

A fast and easy to realize in a practical laboratory conditions GC/MS/MS method for determination of OPPs chlorpyrifos-methyl, parathion pirimiphos-methyl and diazinon was developed and validate. Two different methods for sample preparation were used as well as two solvent extraction systems were tested during this study. The created modified QuEChERS method reveal better results than Silica-gel clean up procedure. The acetonitrile:hexane combination was preferred because of better separation between the two solvents and easily removal of hexane layer. The created method is easy and fast for realization and it led to obtaining of pure analytical results for target compounds fitting with requirements of the European legislation Document № SANTE/12682/2019.

\section{ACKNOWLEDGEMENTS}

The authors would like to thank to Central Laboratory of Veterinary Control and Ecology, Bulgarian Food Safety Agency, Sofia, Bulgaria, for the opportunity to use their specific equipment.

\section{REFERENCES}

1. Whitford, F. The Benefits of Pesticides, A Story Worth Telling. Purdue Extension, https://www.extension.purdue.edu/extmedia/ ppp/ppp-70.pdf, 2009. Retrieved March 27, 2020.

2. Gilden, R. C.; Huffling, K.; Sattler, B. Pesticides and health risks. J. Obstet. Gynecol. Neonatal Nurs. 2010, 39, 103. https://doi.org/10. 1111/j.1552-6909.2009.01092.x.

3. Kiljanek, T.; Niewiadowska, A.; Semeniuk, S. Determination of organophosphorus pesticide residues in the liver by gas chromatography with flame photometric detection. Bull. Vet. Inst. Pulawy 2011, 55731 .

4. Colović, M. B.; Krstić, D. Z.; Lazarević-Pašti, T. D.; Bondžić, A. M.; Vasić, V. M. Acetylcholinesterase inhibitors: pharmacology and toxicology. Curr. Neuropharmac. 2013, 11, 315. https://doi.org/10. 2174/1570159X11311030006.

5. Commission Implementing Regulation (EU) 2018/555 of 9 April 2018 Concerning a Coordinated Multiannual Control Programme of the Union for 2019, 2020 and 2021 to Ensure Compliance with Maximum Residue Levels of Pesticides and to Assess the Consumer
Exposure to Pesticide Residues in and on Food of Plant and Animal Origin, https://eur-lex.europa.eu/eli/reg_impl/2018/555/oj. Retrieved March 27, 2020.

6. Stoykova, T.; Yankovska-Stefenova, T.; Yotova, L. Danalev, D. Modified QuECHERS method for determination of methomyl, aldicarb, carbofuran and propoxur in liver. Chemistry: Bulg. J. Sci. Educ. 2015, 24, 390.

7. Yaneva, S.; Stoykova, I.; Danalev, D.; Yotova, L. Determination of $\mathrm{N}$-methyl carbamates in a liver sample using an optical biosensor. JCTM 2019, 54, 362.

8. Ledoux, M. Analytical methods applied to the determination of pesticide residues in foods of animal origin. A review of the past two decades. J. Chromatogr. A 2011, 1218, 1021.

9. Anastassiades, M.; Lehotay, S. J.; Stajnbaher, D.; Schenck, F. J. Fast and easy multiresidue method employing acetonitrile extraction/partitioning and "dispersive solid-phase extraction" for the determination of pesticide residues in produce. J. AOAC Int. 2003, 86, 412.

10. Aguilera-Luiz, M. M.; Vidal, J. L. M.; Romero-González, R.; Frenich, A. G. Multi-residue determination of veterinary drugs in milk by ultra-high pressure liquid chromatograph- tandem mass spectrometry. J. Chromatogr. A 2008, 1205, 10.

11. Cunha, S. C.; Lehotay, S. J.; Mastovska, K.; Fernandes, J. O.; Beatriz, M.; Oliveira, P. P. Evaluation of the QuEChERS sample preparation approach for the analysis of pesticide residues in olives. J. Sep. Sci. 2007, 30, 620 .

12. Lehotay, S. J.; Mastvoska, K.; Yun, S. J. Evaluation of two fast and easy methods for pesticide residue analysis in fatty food matrixes. $J$. AOAC Int. 2005, 88, 630.

13. Lehotay, S. J.; Son, K. A.; Kwon, H.; Koesukwiwat, U.; Fu, W.; Mastovska, K.; Hoh, E.; Leepipatpiboon, N. Comparison of QuEChERS sample preparation methods for the analysis of pesticide residues in fruits and vegetables. J. Chromatogr. A 2010, 1217, 2548.

14. Beyer, A.; Biziuk, M. Applications of sample preparation techniques in the analysis of pesticides and PCBs in food. Food Chemistry 2008, 108, 669 .

15. Beyer, A.; Biziuk, M. Analytical methods for the routinely evaluation of pesticide residues in lemon fruits and by products. SN App. Sci. 2019, 1, 618.

16. BDS EN 1528-1:2001 Fatty food - Determination of pesticides and polychlorinated biphenyls (PCBs). Part 1: General, Bulgarian Institute for Standardization.

17. Przybylski, C.; Segard, C. Method for routine screening of pesticides and metabolites in meat based baby-food using extraction and gas chromatography-mass spectrometry, J. Sep. Sci. 2009, 32, 1858.

18. Castillo, M.; Carbonell, E.; Gonzàlez, C.; Miralles-Marco, A. Pesticide Residue Analysis in Animal Origin Food: Procedure Proposal and Evaluation for Lipophilic Pesticides, Open Access Book "Pesticides - Resent Trends in Pesticides Residues Assay", ISBN 978-953-51-0681-4, Chapter 3; Publisher InTech, 2012.

19. Main changes introduced in Document $\mathrm{N}^{\circ}$ SANTE/12682/2019 with respect to the previous version (Document $\mathrm{N}^{\circ}$ SANTE/ 11813/2017). Guidance document on analytical quality control and validation procedures for pesticide residues analysis in food and feed.

20. EURACHEM/CITAC Guide CG 4, Quantifying Uncertainty in Analytical Measurement, Ellison, S. L. R.; Williams A. Eds, 3rd ed., https://www.eurachem.org/images/stories/Guides/pdf/QUAM2012_ P1.pdf. Retrieved March 27, 2020. 
21. Kiljanek, T.; Niewiadowska, A.; Semeniuk, S. Determination of organophosphorus pesticide residues in the liver by gas chromatography with flame photometric detection. Bull. Vet. Inst. Pulawy 2011, 55, 731.

22. Botitsi, H. V.; Garbis, S. D.; Economou, A.; Tsipi, D. F. Current mass spectrometry strategies for the analysis of pesticides and their metabolites in food and water matrices. Mass Spectrom. Rev. 2011, 30, 907.

23. Chung, S. W. C.; Chen, B. L. S. Determination of organochlorine pesticide residues in fatty foods: A critical review on the analytical methods and their testing capabilities. J. Chromatogr. A 2011, 1218, 5555.

24. Zanella, R.; Prestes, O. D.; Do Amaral, F. C.; Martins, M. L.; Bohrer, A. M. Modern Sample Preparation Methods for Pesticide Multiresidue Determination in Foods of Animal Origin by Chromatographic-mass Spectrometric Techniques. Open access Book: The impact of pesticides. AcademyPublish.org, 2012, ISBN 978-09835850-9-1, 355-379. 